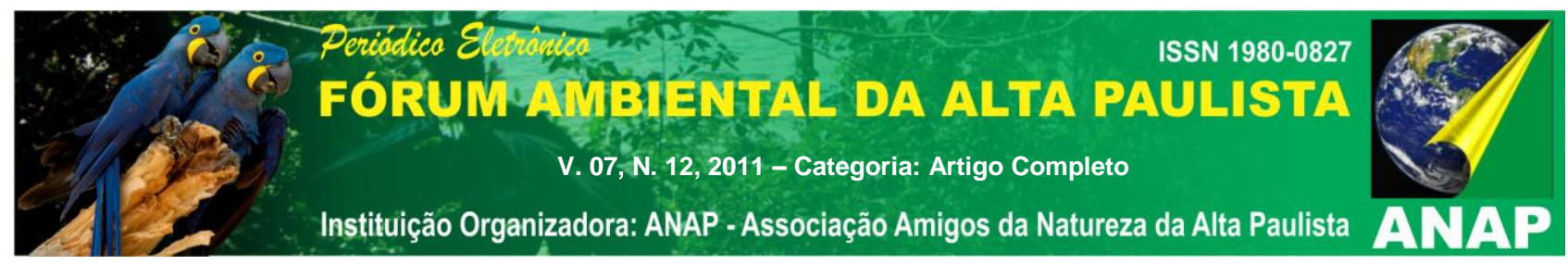

\title{
ASPECTOS JURÍDICOS DA POLUIÇÃO AMBIENTAL NO PÓLO PETROQUÍMICO DE CUBATÃO: O CASO RHODIA
}

\author{
Maria Luiza Machado Granziera ${ }^{1}$ \\ Luís Felipe Carrari de Amorim ${ }^{2}$ \\ Fernanda Barboza de Oliveira ${ }^{3}$
}

RESUMO: O caso do passivo ambiental dos resíduos organoclorados gerados pela empresa Rhodia é significativo para a análise da responsabilidade civil da indústria por degradação ambiental. O presente trabalho propõe o estudo do desenvolvimento das atividades da Rhodia no polo petroquímico na cidade de Cubatão, do produto e dos resíduos gerados pela atividade petroquímica, da legislação protetiva quanto à produção, comercialização e uso dos agrotóxicos organoclorados, da responsabilidade civil ambiental da indústria geradora de resíduos sólidos e do manejo da ação civil pública para promover a conservação e a reparação dos bens ambientais em face dessa forma de degradação. O enfoque traz a atualização da posição das duas ações civis públicas, em trâmite nas Comarcas de São Vicente e Cubatão. Os procedimentos adotados compreendem a análise doutrinária acerca dos tópicos abordados, comparando-a com a atividade judiciária empregada na responsabilização da Rhodia pela contaminação dos solos com os resíduos dos organoclorados. A escassez de fontes primárias de dados sobre o assunto outrossim recomenda a busca por fontes secundárias, como os relatos de associações e sindicatos de vítimas envolvidas no caso. Essas fontes podem constituir o cerne dos fundamentos da pesquisa pela força da credibilidade dos relatos das vítimas do evento. Como resultado, concluímos pela aplicação preferencial de institutos modernos de gestão ambiental, como no caso da logística reversa.

Palavras chave: Direito Ambiental; Responsabilidade Civil; resíduos industriais; poluentes organoclorados.

\footnotetext{
${ }^{1}$ Advogada e consultora. Mestre e Doutora em Direito pela USP. Professora do Programa de Mestrado em Direito Ambiental da Unisantos. Autora dos livros Direito de Águas e Direito Ambiental, publicados pela Editora Atlas. marialuiza.granziera@gmail.com.

${ }^{2}$ Advogado associado do escritório Ruy de Mello Miller. Mestre em Direito pela Unisantos, com bolsa CAPES. luisfelipe@miller.adv.br.
} 


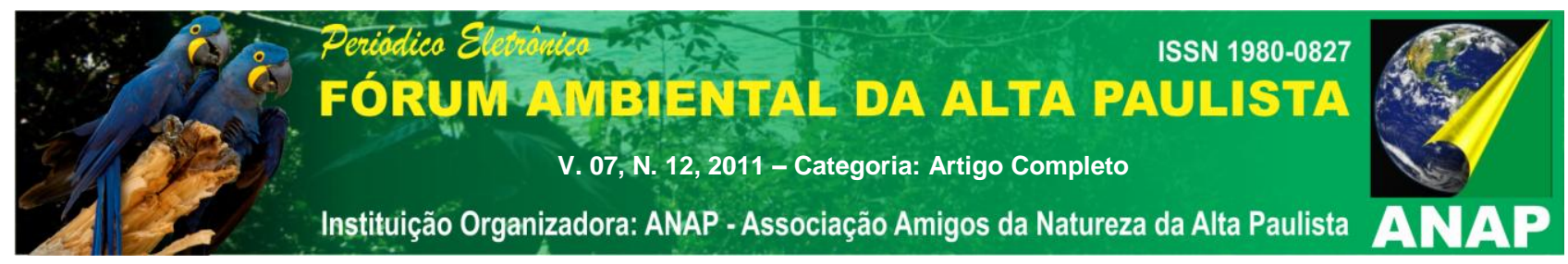

\section{INTRODUÇÃO}

A ineficácia do gerenciamento dos resíduos industriais pode representar uma ameaça à vida humana. No último século, com o avanço das atividades industriais, acidentes envolvendo a destinação final dos resíduos industriais foram registrados pelo mundo. Da internação de pescadores da Baía de Minamata, no Japão, em 1956, à contaminação do rio Pomba, no Brasil, em 2003, são registrados eventos potencialmente poluidores envolvendo o descarte de materiais gerados pelo processo industrial.

A indústria, como se sabe, utiliza significativa quantidade de recursos naturais, transformando-os em produtos de circulação nos mercados de consumo. Sua função é atender às necessidades dos consumidores, concomitantemente lucrando com a posição de fornecedora.

Nos municípios brasileiros, as indústrias se concentraram em grandes áreas, chamadas de pólos, onde se reúnem devido a necessidades comuns de energia, logística, vantagens fiscais e recursos. Na Baixada Santista, região metropolitana e litorânea do Estado de São Paulo, a cidade de Cubatão passou a abrigar o foco emergente das indústrias brasileiras com mais intensidade a partir da década de 1960. Na época, acreditava-se que a localização geográfica, próxima à encosta da Serra do Mar e em meio à mata, seria favorável em termos de segurança nacional. Porém, com o tempo constatou-se o surgimento de complicações ambientais em função dessa escolha.

Os casos envolvendo poluição ao ambiente e à saúde humana mostraram a fragilidade da área quanto à contenção de resíduos contaminantes. A contaminação do ar, do solo e das águas por rejeitos industriais em Cubatão chegou a atingir índices muito superiores ao tolerável pelo corpo humano. As internações, as deformidades congênitas e as concentrações de substâncias letais ao longo das décadas foram episódios deflagradores de políticas em desatendimento à questão ambiental. A atividade industrial cresceu, inspirada no modelo desenvolvimentista, com a autorização dos Poderes Públicos, mas sem equacionar as consequências ao ambiente.

\footnotetext{
${ }^{3}$ Advogada. Pós-graduanda em Direito Ambiental pela PUC/SP. nandinha bo@hotmail.com.
} 


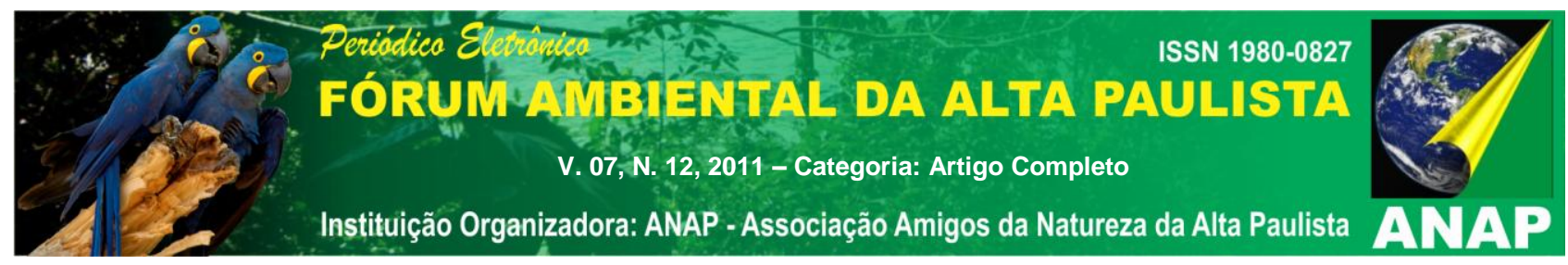

Em 1980, foi promulgada no Brasil a primeira lei ambiental de impacto abrangente: a Lei de Política Nacional do Meio Ambiente. Apesar de não discriminar as atividades poluidoras ou as tutelas específicas para cada espécie de poluição, a lei trouxe importantes mecanismos para a responsabilização dos poluidores. Dentre eles a possibilidade de condenação civil sem considerar o elemento culpa, na responsabilidade civil objetiva.

A legislação ambiental surgiu no intuito de redistribuir na sociedade as consequências pelos riscos da atividade econômica. Ou seja, no caso da indústria, por ser uma atividade extremamente rentável, e considerando que, por razões de anonimato ou desconhecimento dos seus agentes diretos, os efeitos da poluição nem sempre traziam reparação às vítimas, a legislação passou a exigir, como medida preventiva, o estudo preliminar de impacto das atividades, bem como sujeitou o funcionamento à renovação periódica das autorizações. Além disso, como medida repressiva, foram modernizados os mecanismos para a reparação do ambiente como patrimônio social.

O presente trabalho enfocará a experiência da Justiça em buscar a reparação por poluição de organoclorados no caso Rhodia nas cidades de São Vicente e Cubatão.

\section{HISTÓRICO DO CASO RHODIA}

Na década de 1970, operou na cidade de Cubatão a fábrica da Clorogil S/A Indústria Química. Sua atividade envolveu a manipulação de produtos como o cloro e a soda cáustica. Os resíduos químicos gerados pela fábrica foram depositados em áreas impróprias, conhecidas como "lixões", inclusive próximas às margens dos rios.

Em 1976, a fábrica foi vendida à empresa Rhodia Indústrias Químicas e Têxteis S/A, do grupo estatal francês Rhône-Poulenc. Ao adquiri-la, a Rhodia, todavia deu continuidade ao descarte dos resíduos nos "lixões".

Com o tempo, os resíduos depositados formaram uma área difusa de contaminação, afetando principalmente o Vale dos Pilões. Essa região servia como ponto de captação de águas pela SABESP para o abastecimento público. Outrossim, era usada 


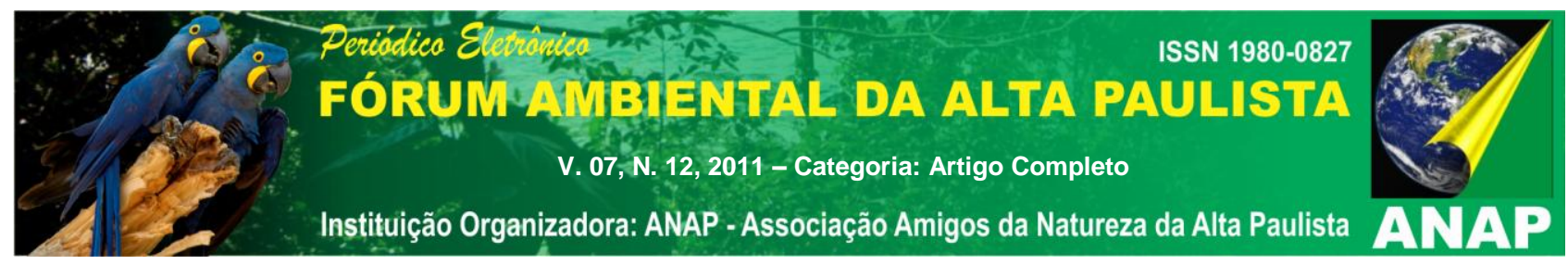

para a irrigação de culturas de banana para a subsistência e para a dessedentação de pequenos animais.

$\mathrm{Na}$ cidade de São Vicente, o bairro do Samaritá foi o principal foco da contaminação. Áreas de concentração populacional, assim como mangues e rios, foram diretamente expostas aos efeitos de toneladas de resíduos sólidos industriais ${ }^{4}$.

A notícia da morte por contaminação de um dos funcionários da fábrica chamou a atenção da opinião pública. Após a divulgação do caso na mídia, em 1978, a área que manipulava pentaclorofenol foi fechada ${ }^{5}$. Posteriormente, outras mortes se seguiriam, de funcionários vítimas da contaminação e com a saúde já bastante debilitada devido à exposição.

Os principais resíduos contaminantes identificados nessas áreas foram 0 hexaclorobenzeno e o pentaclorofenato de sódio ${ }^{6}$.

\section{POLUENTES ORGANOCLORADOS}

Os produtos organoclorados são utilizados como defensivos agrícolas. São empregados nas lavouras com o objetivo de conter os ataques de pragas e insetos, aumentando assim a eficiência dos recursos agrícolas e a produtividade dos alimentos de origem plantada. Seu custo é baixo e o potencial de aniquilação é alto.

Em razão dos seus benefícios econômicos, o emprego desses produtos aumentou gradativamente. Porém, sua ampla utilização favoreceu a multiplicação de insetos resistentes aos efeitos letais. Além disso, os resíduos gerados pelo uso dos produtos organoclorados, descartados inadequadamente, causam degradação ambiental.

Depositados no solo, esses resíduos são transportados em grandes escalas pelas águas das chuvas, que arrastam a cobertura vegetal e parte do solo, chegando às águas superficiais como rios e lagos. Através do solo, os resíduos podem atingir as águas

\footnotetext{
${ }^{4}$ MESQUITA, 1994.

${ }^{5}$ A TRIBUNA, 1978.

${ }^{6}$ PRANDI, 2006.
} 


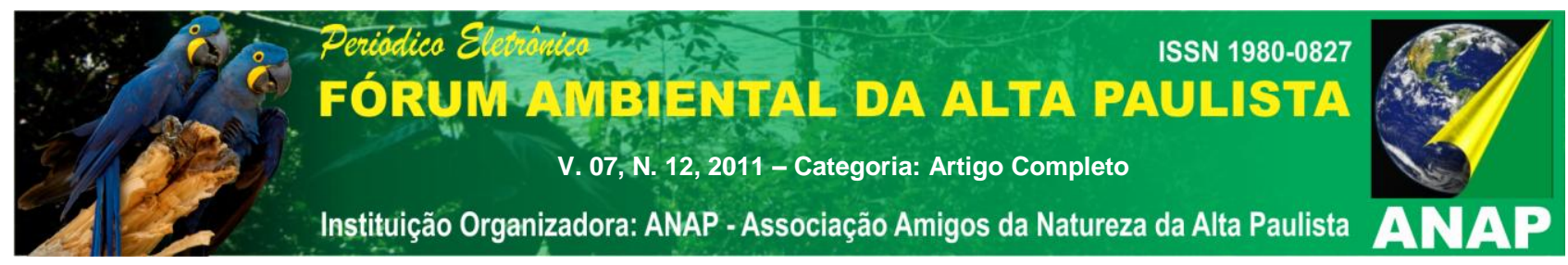

subterrâneas e se misturar em águas de poços de uso doméstico e que saciam a sede humana e a dos animais ${ }^{7}$.

Segundo a classificação da NBR 10.005, da ABNT, os produtos químicos são classificados segundo sua periculosidade em tóxicos, corrosivos, inflamáveis e reativos. Alguns tipos de produtos organoclorados, como os pesticidas, são considerados altamente tóxicos e responsáveis pela contaminação de pessoas e animais, bem como do ar, lagos, oceanos ${ }^{8}$.

Os resíduos destes produtos são ainda considerados responsáveis pela extinção de populações inteiras de aves, focas, entre outros animais e até mesmo pela infertilidade dos mesmos. Há estudos científicos que apontam alterações dos organoclorados no funcionamento interno do organismo humano, causando defeitos congênitos, enfraquecimento do sistema imunológico e alteração dos níveis hormonais ${ }^{9}$.

Os resíduos organoclorados são persistentes e biocumulativos ${ }^{10}$. Podem persistir na água, nos solos e nos alimentos ${ }^{11}$. Por tal razão são apontados, entre os diversos resíduos químicos tóxicos, como contaminadores mundiais.

É de extrema importância o acompanhamento pelo Poder Público dos locais em que estes produtos continuam sendo utilizados, já que o seu poder de contaminação é elevado, colocando o ambiente em risco constante.

\section{LEGISLAÇÃO PROTETIVA}

A proteção legal em face dos resíduos sólidos concentra-se na destinação a ser dada aos materiais descartados. Como já tivemos a oportunidade de balizar, "o problema que se coloca em relação aos resíduos sólidos consiste na sua disposição final, que deve ser de forma ambientalmente adequada". ${ }^{12}$

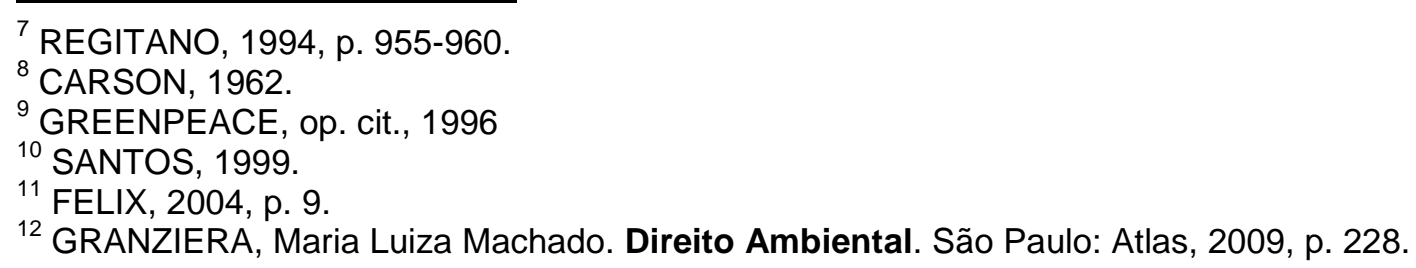




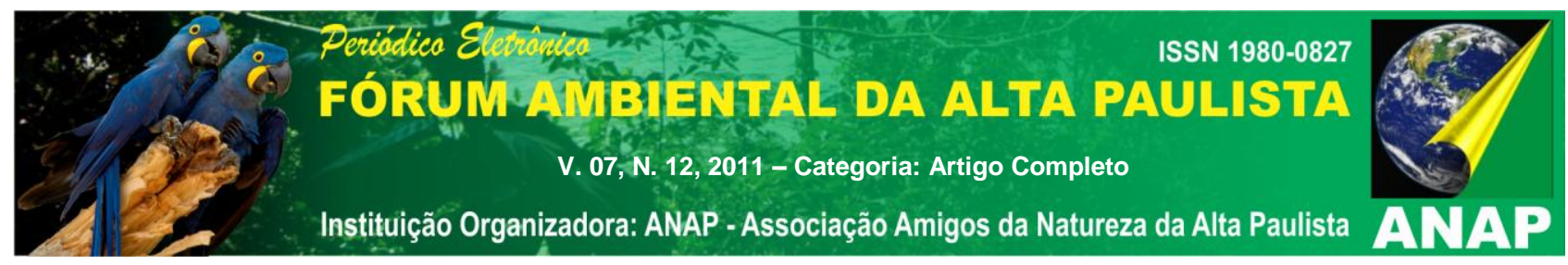

No caso dos defensivos agrícolas, tendo em vista os prejuízos ambientais desde a década de 1970, o uso de pesticidas organoclorados tem sido gradativamente reduzido a aplicações específicas em vários lugares do mundo e, por seu poder cancerígeno e danos ao meio ambiente, o seu uso acabou sendo limitado, e em alguns países, extinto ${ }^{13}$.

Os produtos organoclorados passaram a ser substituídos por pesticidas mais caros, menos persistentes e com tecnologia mais avançada ${ }^{14}$.

Os resíduos sólidos, de maneira geral, eram mencionados pela Lei $n^{\circ} 2.312 / 54$, que em seu artigo 12 estatuía: "a coleta, o transporte e o destino final do lixo deverão processar-se em condições que não tragam inconveniente à saúde e ao bem estar públicos" ${ }^{15}$; e pelo Código Nacional de Saúde, Decreto no 49.974-A $/ 61^{16}$.

A Portaria MINTER (Ministério do Interior) n 53/79 dispôs sobre a fiscalização dos resíduos sólidos, derivados de todo trabalho humano, como prevenção da poluição no solo, nas águas e ar. A Portaria ANVISA no $329 / 85{ }^{17}$, dispôs sobre a proibição no Brasil das atividades de comércio, uso e distribuição de produtos agrotóxicos organoclorados, voltados à agropecuária. Evidentemente, havia comprometimento na eficácia dos dispositivos, tendo em vista a natureza restrita do alcance subjetivo da norma.

O advento da Constituição Federal de 1988 trouxe significativo avanço protetivo na medida em que atribuiu ao Poder Público o dever de controlar as atividades econômicas que comportem risco à qualidade de vida e ao meio ambiente (art. 225, par. 1ํ, V). Releva mencionar o conceito de "sociedade de risco", que "designa um estágio da modernidade na qual começam a tomar corpo as ameaças produzidas até então pelo modelo econômico da sociedade industrial ${ }^{18}$. A Política Nacional do Meio Ambiente de 1981 e a $\mathrm{CF} / 88$ vieram dar resposta dessa demanda.

\footnotetext{
${ }_{14}^{13}$ ANVISA, 1985, p. 1.

${ }^{14}$ CONSTENLA, 1998 , p. 123-147.

${ }^{15}$ LEI n. 2.312, de 03 de setembro de 1954 "Estabelece normas gerais sobre defesa e proteção da saúde".

${ }^{16}$ DECRETO n 49.974-A, de 21 de janeiro de 1961 - "Regulamenta, sob a denominação de Código Nacional de Saúde, a Lei $n^{\circ}$. 2.312, de 3 de setembro de 1954, de Normas Gerais Sobre Defesa e Proteção da Saúde".

${ }_{17}$ PORTARIA $n^{\circ} 329 / 85$.

${ }^{18}$ LEITE, José Rubens Morato; AYALA, Patryck de Araújo. Dano Ambiental: do individual ao coletivo extrapatrimonial. 4. ed. São Paulo: RT, 2011, p. 115.
} 


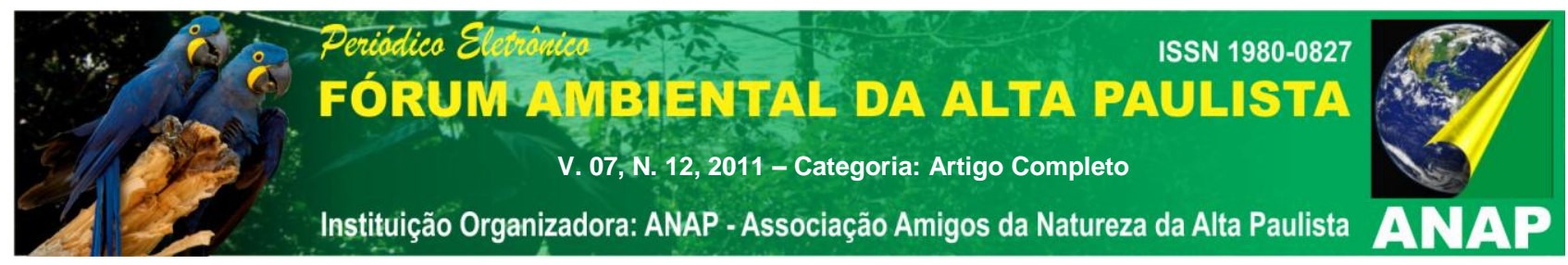

Nesta senda, a Lei $n^{\circ} 7.802 / 89$, regulamentada pelo Decreto $n^{\circ}$ 98.816/90 e pelo Decreto Federal no 4.074/2002, unificou o controle da exploração comercial dos agrotóxicos.

Segundo a Lei n7.802/89, art. 2º̣, I, agrotóxicos são:

\begin{abstract}
os produtos e os agentes de processos físicos, químicos ou biológicos, destinados ao uso nos setores de produção, no armazenamento e beneficiamento de produtos agrícolas, nas pastagens, na proteção de florestas, nativas ou implantadas, e de outros ecossistemas e também de ambientes urbanos, hídricos e industriais, cuja finalidade seja alterar a composição da flora ou da fauna, a fim de preservá-las da ação danosa de seres vivos considerados nocivos; substâncias e produtos, empregados como desfolhantes, dessecantes, estimuladores e inibidores de crescimento.
\end{abstract}

O parágrafo único do artigo 20 da Lei $n^{\circ}$ 7.802/89 exigiu a imediata reavaliação dos registros de defensivos contendo os organoclorados, adequando-se à lei. Atualmente, tal ato é complexo e compete ao Ministério da Agricultura, Pecuária e Abastecimento (MAPA), ao Ministério da Saúde (MS) e ao Ministério do Meio Ambiente (MMA). No entanto, não houve na lei proibição expressa da sua exploração ou uso, ficando pendente de ato do Poder Público, que atualmente permite em casos de conservação de madeira.

Segundo alguns, permitir um nível aceitável de utilização de certos organoclorados é uma medida desastrosa, não ajudando em nada excluir os organoclorados ${ }^{19}$.

O Decreto $n^{\circ} 3.694 / 2000^{20}$ trata do controle e da fiscalização de agrotóxicos. Pelo Decreto:

- Governo Federal faz obrigatório o registro de matérias primas, composição inertes e aditivos utilizados na fabricação de praguicidas, como também tem que ser inscritos antecipadamente junto ao órgão. A permissão é concedida ou caçada, ficando na dependência do grau de periculosidade que o produto traz ao ambiente, aos recursos naturais e a saúde dos trabalhadores. ${ }^{21}$

Com o surgimento da Lei no 12.305/10, as políticas públicas sobre o descarte de resíduos foram renovadas. Destacamos o instrumento de monitoramento e fiscalização

\footnotetext{
${ }^{19}$ GREENPEACE, 1996.

${ }^{20}$ DECRETO $n^{\circ} 3.694$, de 21 de dezembro de 2000 - "Que dispõe sobre o controle e a fiscalização de agrotóxicos, e dá outras providências".

${ }^{21}$ CAMPOS, 2003.
} 


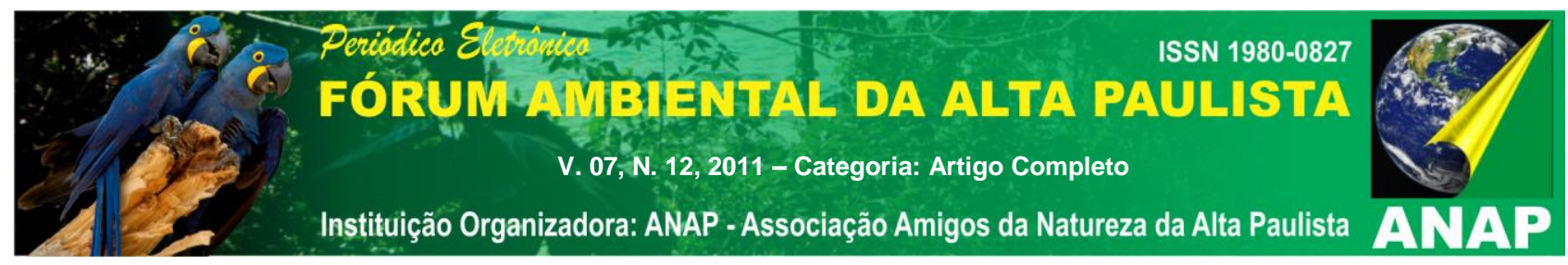

agropecuária ( $\left.8^{\circ}, \mathrm{V}\right)$; a classificação dos organoclorados como insumos dos "resíduos agrossilvopastoris” (art. 13, I, “i”); sua inclusão dentre o objeto de gestão de serviços públicos nos planos estaduais voltados a micorrregiões (art. 16, par. 3ํ); a possibilidade de exigência das empresas agrossilvopastoris de elaborarem plano de gerenciamento dos resíduos sólidos (art. 20, V); a obrigação de aplicar a logística reversa aos fornecedores de agrotóxicos, seus resíduos e embalagens (art. 33, I).

A instituição da logística reversa perante os fornecedores de organoclorados consiste na prevenção e no reforço da responsabilização em face dos riscos e dos prejuízos ambientais.

É medida preventiva porque, ainda que na potencialidade da lesão, compete ao fornecedor sujeitar-se à adoção dos métodos de redução e mitigação dos impactos ambientais, tais como facilitar o seu descarte apropriado pelos consumidores. A exemplo do espírito da Convenção de Basileia de 1989, acolhe a ideia de que a maneira mais eficaz de proteção ambiental contra os resíduos é a redução quantitativa e periculosa de sua geração ao mínimo.

É outrossim medida de reforço porque revela nítida a responsabilidade do fornecedor pelos riscos oriundos da sua atividade.

\section{RESPONSABILIDADE CIVIL POR POLUIÇÃo CAUSADA POR RESídUOS INDUSTRIAIS}

A ineficácia da gestão dos resíduos industriais invariavelmente conduz à poluição ambiental. Sem atingir seus objetivos, a má gestão dos resíduos pode provocar danos ao ambiente. A tutela em caso da ocorrência desses danos é repressiva e repousa no instituto da responsabilidade civil.

A responsabilidade civil está voltada para a recomposição patrimonial. No caso da poluição, a sanção aplicada ao poluidor é a condenação ao pagamento de uma indenização em pecúnia, considerando a proporção da lesão causada, entre outros fatores. Outras medidas poderão ser impostas ao poluidor com o fito de conter ou evitar a 


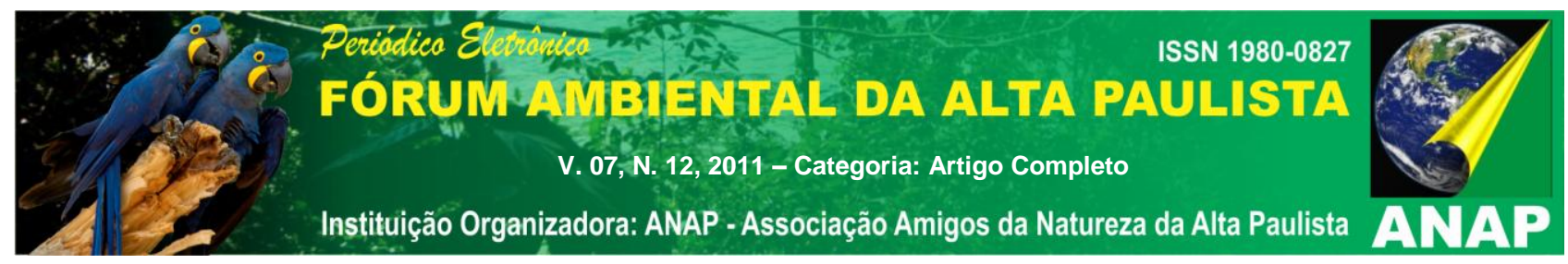

continuação dos danos. São obrigações de fazer e de não fazer, e que se cumulam com a imposição de indenização monetária (art. 3ํ, Lei no 7.347/85).

As obrigações cominatórias são consideradas mais eficazes, pois se destinam à suspensão e à recuperação dos danos ambientais. Sua imposição é preferencial à condenação indenizatória, tendo em vista as dificuldades de fixação satisfatória das indenizações e de vinculação de sua destinação.

Por um lado, a liquidação das indenizações é atividade tormentosa e insatisfatória diante da celeuma e incerteza científica quanto à mensuração dos prejuízos. Por outro, a lei prevê a destinação da indenização a um fundo específico, que na prática ou não existe ou não funciona. Inevitavelmente, isso converte o resultado da condenação em mero depósito em dinheiro junto às instituições financeiras oficiais (Lei no 7.347/85, art. 13, par. único).

Como no Direito Ambiental a responsabilidade civil é objetiva, descabe indagar acerca do elemento subjetivo da culpa. Para haver o dever de reparar, é suficiente que a atividade provoque dano ao ambiente, e que esse dano esteja diretamente ligado à atividade numa relação causal.

Por sua vez, a responsabilidade civil do gerador de resíduos segue a regra from cradle to grave do direito americano. Ou seja, pelas características peculiares dos resíduos, tais como toxicidade, corrosividade, inflamabilidade e reatividade, o produtor pode continuar responsável por eles, ainda que os tenha entregado a terceiros, tais como transportadores, e independentemente da existência de cláusulas de transmissão da responsabilidade.

O desenvolvimento da atividade industrial e o depósito em solo dos resíduos industriais é bem anterior ao conhecimento mais profundo dos seus efeitos de degradação ambiental. Essa situação fez surgir o chamado "passivo ambiental", e que consiste no "total de dívidas contraídas, em razão de a empresa encontrar-se em desconformidade com a legislação ambiental"22.

Evidentemente, muitos destes passivos surgiram antes do aperfeiçoamento da legislação ambiental. Todavia, em razão dos prejuízos causados aos bens ambientais da sociedade, cuja tutela remonta a tempos mais distantes, a responsabilidade da atividade

\footnotetext{
${ }^{22}$ GRANZIERA, Maria Luiza Machado. Direito Ambiental. São Paulo: Atlas, 2009, p. 231.
} 


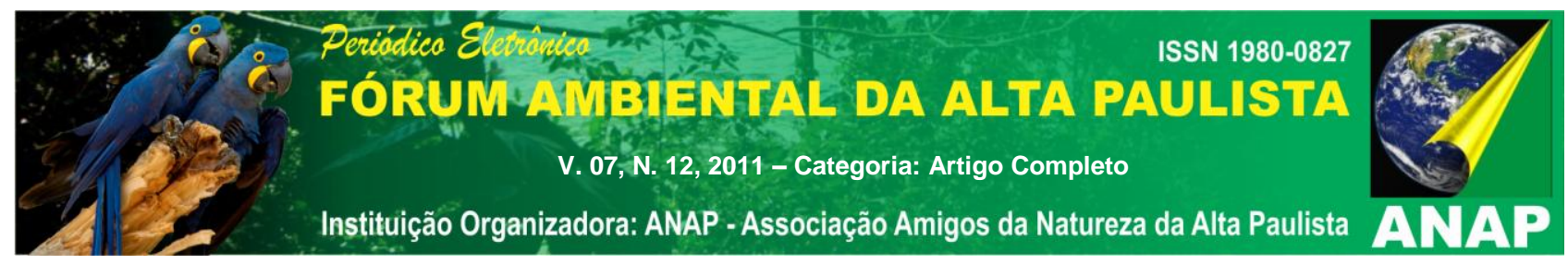

industrial pela poluição causada por resíduos sólidos poderá em alguns casos retroagir para buscar a indenização das vítimas.

Assim sendo, a indústria pode ser responsável por indenizar a sociedade pelos danos que causar ao ambiente pelo depósito de resíduos poluentes. Sendo assim, o desenvolvimento da atividade industrial poderá se sujeitar a reparar os prejuízos advindos da exploração dos recursos naturais, considerando ser dever da indústria promover o adequado gerenciamento dos seus resíduos, pondo a salvo o ambiente de sofrer os efeitos da poluição.

O maior desafio à condenação da indústria pela poluição causada pelo depósito de resíduos industriais reside exatamente na constatação do dano ambiental e no relacionamento direto entre a atividade industrial e esse dano.

Apesar de se reconhecer a existência de correntes de pensamento que defendem a causalidade pela equivalência dos antecedentes, o que se vê na jurisprudência é uma cautelosa adoção da chamada "teoria da causalidade adequada". Portanto, nem toda a circunstância anterior será considerada como causa por equivalência. Para a maioria dos tribunais brasileiros, é considerado como causa o fato anterior mais idôneo e apto a provocar o efeito poluidor.

A necessidade de delineamento de um nexo causal direto e imediato pode ser visto como elemento de segurança às decisões judiciais. Evita assim a prática de injustiças, como a formação de um consórcio heterogêneo e por demais alargado de responsáveis.

Não se olvida que os mecanismos modernos de facilitação da responsabilização ambiental foram trazidos com fundamento no anonimato dos agentes e na vulnerabilidade das vítimas. Onde estes fatores forem ausentes, não se justifica o emprego dos facilitadores.

Neste sentido, pode-se dizer que a composição de responsáveis solidários dependerá bastante da natureza do objeto da indústria. Por exemplo, uma fábrica de tecidos não deveria responder por um acidente rodoviário pelo transporte de seus produtos. Afinal, os tecidos são inertes e não causam mal ao ambiente. Porém, se falarmos de um acidente rodoviário envolvendo o transporte de produtos tóxicos, como os organoclorados, é razoável se estender a responsabilidade, além do transportador, ao 


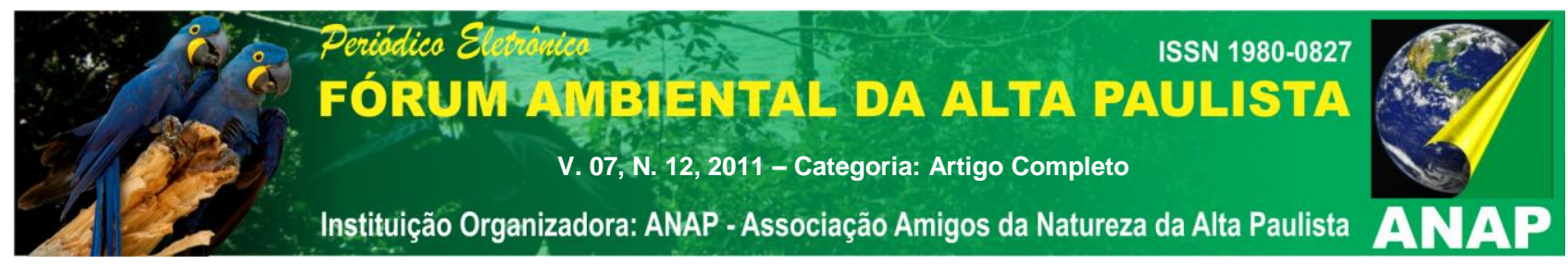

fabricante dos produtos ${ }^{23}$, desde que respeitada a proporcionalidade constatada para cada caso.

No caso dos resíduos organoclorados, assim como os produtos, eles certamente são decorrentes do processo de fabricação. Portanto, sua razão de existir no mundo está ligada ao objeto da indústria. Sem a atividade de produção industrial, esses resíduos não chegariam ao ambiente. Caso o seu descarte seja inadequado, ou as consequências do descarte efetuado por terceiros, resta límpida a responsabilidade, seja ela exclusiva, seja ela solidária. Assim, está satisfeita a regra do from cradle to grave.

Chamamos a atenção para o caso dos sítios órfãos contaminados. Nestes casos, há dificuldade em apontar o gerador do resíduo, seja porque a indústria que lá operava deixou de existir sob condições anormais e não se encontram responsáveis, seja porque somente se identifica o proprietário da área, mas não o gerador do resíduo.

Além da possibilidade de responsabilizar os ex-sócios da empresa ou os atuais proprietários do terreno contaminado, nos limites de suas respectivas responsabilidades, pode-se dizer que, a depender do grau de omissão, há ainda a responsabilização do Poder Público pelas obrigações para a remoção e descontaminação dos solos degradados nos sítios órfãos.

\section{A POLUIÇÃo CAUSADA POR RESÍDUOS INDUSTRIAIS E A AÇÃO CIVIL PÚBLICA}

A fim de dar efetividade ao Direito Ambiental, um conjunto de procedimentos judiciais e extrajudicias podem ser executados. Este conjunto deve observar o princípio da prevenção e da precaução em consonância com o princípio da responsabilização, diminuindo assim o risco de irreversibilidade do dano ambiental.

A Lei no 7.347/85 deu os contornos para a Ação Civil Pública, uma ação coletiva titularizada pelos representantes jurídicos dos interesses da sociedade. Esses legitimados, além do Ministério Público, são o Estado e suas pessoas jurídicas e as associações civis de proteção aos interesses coletivos e difusos, a exemplo dos ambientais (art. $\left.5^{\circ}\right)$.

\footnotetext{
${ }^{23}$ Esse parece ser o espírito do legislador ao incluir o art. 12 na Lei ํㅜ 8.078/90.
} 


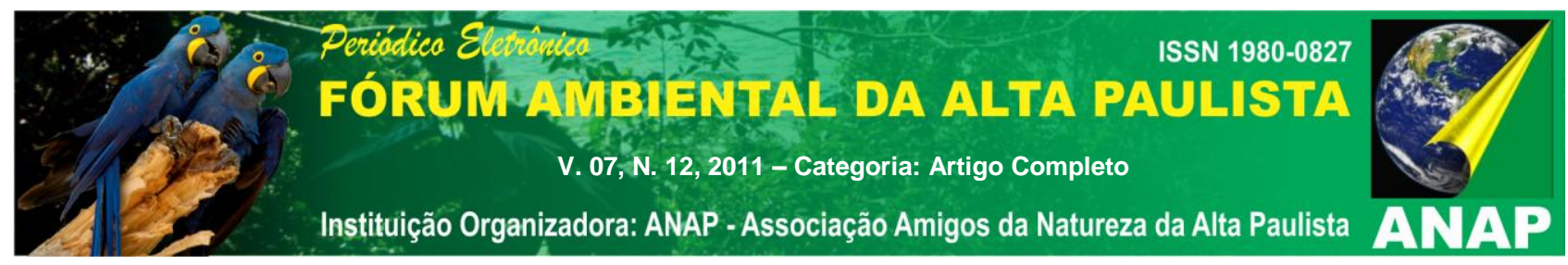

O objetivo da Ação Civil Pública é permitir a cobrança de eventual reparação por danos a estes interesses. Os danos abrangem tanto os materiais quanto os morais (art. $1^{\circ}$, I). Para tanto, a lei permite inclusive a defesa daqueles por meio de medidas cautelares (art. $\left.4^{\circ}\right)$.

A orientação na propositura da Ação Civil Pública, mais frequentemente pelo Ministério Público, corresponde a um processo de tomada de decisão, devendo prevalecer aquela que melhor atenda ao interesse da sociedade. E, sendo assim, ao formular seus pedidos, pode-se afirmar que:

nas condenações em ações jurídicas de lesão ao meio ambiente, não basta ressarcir os danos ambientais em sua totalidade (abrangendo as perdas humanas, sociais, materiais), mas também modificar a técnica de produção, eliminando ou reduzindo a poluição decorrente das atividades correlatas ${ }^{24}$.

No caso Rhodia, o Ministério Público Estadual Paulista e o Município de São Vicente ingressaram com a Ação Civil Pública em desfavor de Rhodia Indústria Química e Têxteis S/A, processo oㅜ 683/1986 (590.01.1986.000183-5), em trâmite perante a $2^{\text {a }}$ Vara Cível da Comarca de São Vicente/SP, distribuído em 13 de junho de 1986, no valor de $\mathrm{C} z \$ 24.858 .800,00^{25}$.

A relação entre os danos ambientais e a atividade industrial da empresa foi comprovada por laudos técnicos, bem como a imprudência na manutenção e limpeza dos locais de depósito do lixo químico. A ação foi julgada procedente em primeiro grau e mantida em grau de recurso, condenando a indústria à criação e manutenção de um sistema próprio de contenção dos poluentes do solo e do aquífero, e a impedir a ocupação humana nas áreas até a efetiva descontaminação. A poluição afetou não só as águas, mas também prejudicou a qualidade do solo e o equilíbrio ecológico.

Informações mais recentes sobre a questão confirmam o início da execução do julgado. Segundo informações colhidas no ano de 2008, o curso processual registrou um incidente na fase de remoção do material contaminado. Por um impasse entre os Ministérios Públicos Estaduais da Bahia e de São Paulo, houve resistência do parquet da Bahia para que os resíduos fossem destinados àquele Estado. Recentemente, a Cetesb

\footnotetext{
${ }^{24}$ CUSTÓDIO, 1990, p. 14.

${ }^{25}$ Disponível em: www.tj.sp.gov.br. Acesso em: 26/06/2011.
} 


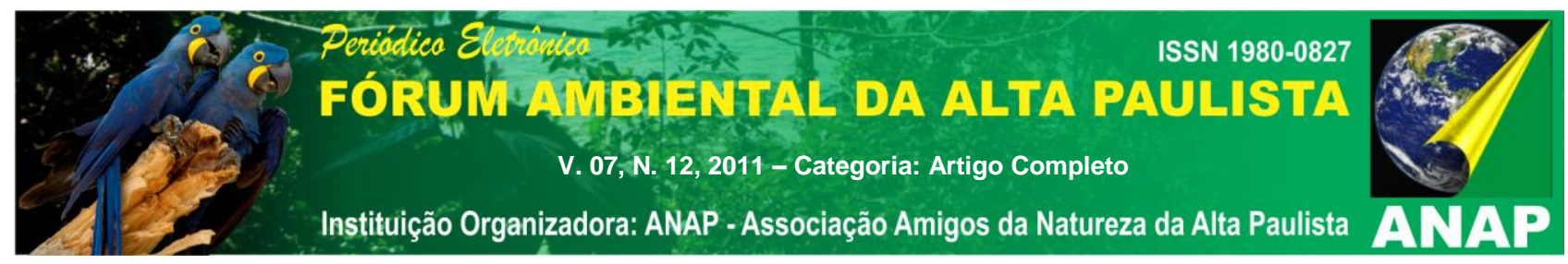

colheu amostras do solo contaminado para análises, a fim de auxiliar na solução do caso, o que aguarda resposta.

Em Cubatão, o Ministério Público Paulista moveu a Ação Civil Pública em face da Rhodia. A ação recebeu o no 944/2010 e tramita perante a $3^{\text {a }}$ Vara Judicial. Os dados a seguir tiveram como fonte a sentença judicial da lavra de Luciana Mourão Castello, Juíza de Direito, assinada em 21 de dezembro de 2010.

O Autor alegou, em síntese, que a Ré assumiu as atividades da empresa Clorogil $\mathrm{S} / \mathrm{A}$, sendo responsável pelo descarte irregular de resíduos industriais (hexaclorobenzeno e pentaclorofenol) às margens do rio Perequê, no interior de seu Parque Ecológico, ocorrido até o ano de 1978. Pediu a condenação da Ré à obrigação de reparar o dano abiental e ao pagamento de indenização pelo irreparável. Houve estudo pericial deferido liminarmente como medida de produção antecipada de provas.

A Defesa alegou não se aplicar ao caso o regime jurídico da Lei no 6.938/81, uma vez que a Clorogil foi adquirida no ano de 1976. Arguiu a ilegitimidade passiva frente à responsabilidade das empresas encarregadas do transporte e destinação dos resíduos. Pediu o reconhecimento da carência da ação por falta de interesse, pois os resíduos foram removidos e incinerados após solicitação da Prefeitura de Cubatão.

A perícia foi deferida, mas não foi realizada. Ao invés, o Autor apresentou parecer pelo julgamento antecipado da lide.

A Cetesb noticiou a adequação da empresa às orientações técnicas, atendendo aos pedidos expostos na petição inicial, situação esta contínua. A atitude da empresa causou o decaimento em $97 \%$ da concentração tóxica original.

Com o fim da instrução processual, a ação foi julgada procedente. A sentença reconheceu o dano ambiental pela alta toxicidade dos resíduos encontrados (carcinogênicos), em padrões muito superiores ao tolerável pela saúde humana e pelo ambiente. Reconheceu ainda a relação causal por ser a Ré a única na região a manusear as substâncias encontradas. Seriam decorrentes da atividade de destilação no processo de produção de tetracloreto de carbono e percloroetileno. A culpa foi atribuída à Ré pela escolha das empresas contratadas e pela falta de fiscalização no transporte e depósito, por ser originariamente sua essa responsabilidade. 


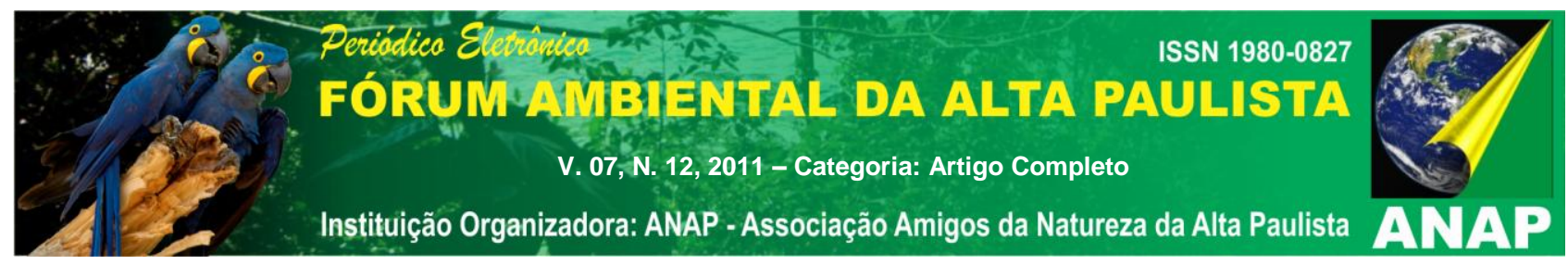

A decisão condenou a Ré ao pagamento de indenização a ser apurada em fase de liquidação, considerando como termo inicial o de deposição dos resíduos no local descrito, encerrando-se com a sua total remediação. Após a sentença, foram interpostos os embargos declaratórios por ambas as partes. Somente os aclaratórios do Autor foram acolhidos.

Na situação atual, a questão depende do julgamento do recurso de apelação pela Ré, contra-arrazoado pelo Autor.

Há ainda em Cubatão uma ação civil pública de no 249/93, movida pelos sindicatos. O tema, todavia, é o ambiente do trabalho, o que pelas limitações impostas pelo presente trabalho impede mais detalhamentos.

\section{CONCLUSÃO}

1.) A atividade de descarte de resíduos sólidos industriais potencialmente poluidores deve ser orientada por atos de gestão, tanto dos fornecedores quanto do Poder Público. Nesse sentido, a Lei oㅜ 12.305, de 2 de agosto de 2010, veio regulamentar essa matéria, explicitando as responsabilidades de cada um que esteja envolvido com esse tema. Sem um planejamento adequado, há a probabilidade de ocorrer poluição pelo descarte inadequado, o que significa um alto grau de risco ao ambiente.

2.) Pesticidas organoclorados são defensivos agrícolas altamente tóxicos e por isso vêm sendo substituídos por tecnologias menos impactantes. Mesmo o seu uso controlado pelo Estado é potencialmente perigoso e deve ser evitado.

3.) O Direito possui dispositivos modernos de proteção do ambiente em face do descarte de produtos organoclorados, destacando-se o instituto da logística reversa, inclusive, como apoio às ações judiciais e ao reconhecimento da responsabilidade civil pela sua poluição.

4.) Em Cubatão e em São Vicente, no final da década de 1970, foram noticiados graves casos de depósitos clandestinos envolvendo a atividade da empresa Rhodia no pólo petroquímico da região. Temos conhecimento de pelo menos três ações públicas buscando a proteção dos interesses difusos ambientais. 


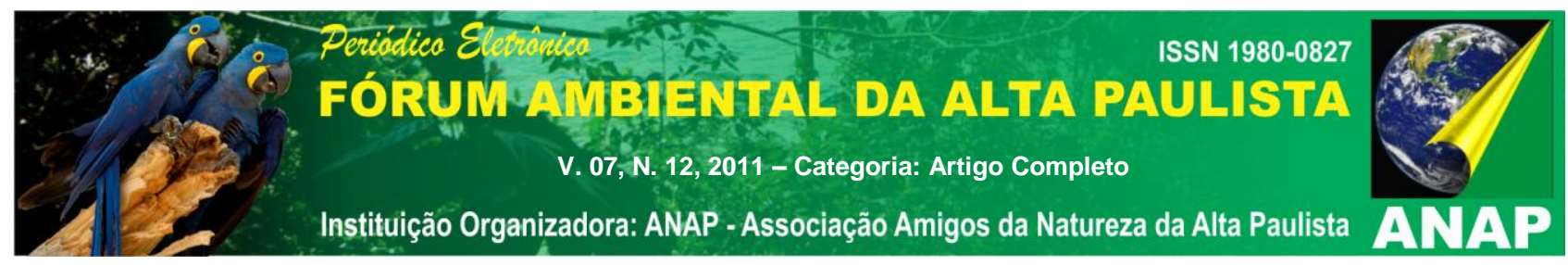

5.) As ações civis públicas, apesar da legislação aplicável, não lograram eficácia até a presente data. Sendo assim, na esteira da nova Lei de Política Nacional dos Resíduos Sólidos, parece-nos preferível a adoção de medidas administrativas de prevenção e de logística reversa como melhor forma de proteger o ambiente face à poluição de resíduos industriais de alta periculosidade.

\section{REFERÊNCIAS}

ANVISA - Agência Nacional de Vigilância Sanitária. Portaria $\mathbf{n}^{\circ}$ 329, 02 de setembro de 1985. Proíbe a comercialização, uso e distribuição de produtos agrotóxicos organoclorados destinados à agropecuária. Brasília, 1985.

A TRIBUNA, Santos. Uni sabe da Rhodia, paralisa produção. Quinta feira, 07 de dezembro de 1978.

CAMPOS, Shirley D. Tóxicos, Intoxicações, Agrotóxicos, Legislação. Maio/2003. Disponível em: http://www.drashirleydecampos.com.br/noticias/9110. Acesso em 19/05/08.

CARSON, Rachel. Silent Spring, 1962. Disponível em: http://www.geocites.com/ esabio/cientistas/raquel carson.htm. Acesso em: 30/04/08.

CONSTENLA, M.A. El uso de plaguicidas em América Latina: tendências e implicaciones ambientales. In: IAEA (Ed.) Pesticides: food andenvironmental implications. IAEA/FAO, Viena, Áustria,1998.

CUSTÓDIO, Helita Barreira. Avaliação de custos ambientais em ações jurídicas de lesão ao meio ambiente. Revista dos Tribunais $n^{\circ}$ 652, fevereiro, 1990.

FELIX, Ana Maria Timóteo. Centro Regional de Saúde Pública do Centro - Risco para a Saúde por exposição a pesticidas. Aveiro, 2004.

GRANZIERA, Maria Luiza Machado. Direito de Águas: Disciplina Jurídica das Águas Doces. 3. ed. São Paulo: Atlas, 2006. 256 p. 


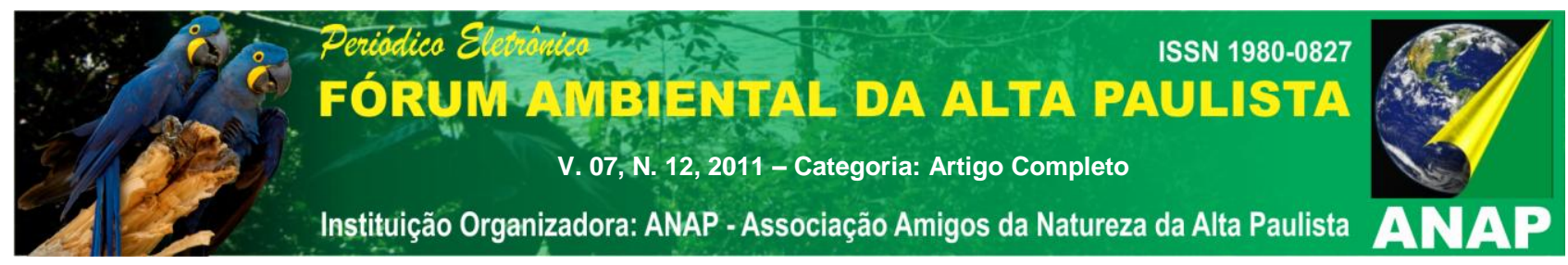

Articulação e negociação institucional na efetividade das políticas ambientais. Revista de Informação Legislativa, no 172, p. 109-117, out./dez. 2006.

Direito Ambiental. São Paulo: Atlas, 2009. 667 p.

GREENPEACE. Os efeitos dos organoclorados na saúde humana, 1996. Disponível em: http://www.greenpeace.org.br/tóxicos/pdf/poluentes.pdf. Acesso em: 30/04/08.

LEITE, José Rubens Morato; AYALA, Patryck de Araújo. Dano Ambiental: do individual ao coletivo extrapatrimonial. 4aㅗ. ed. São Paulo: RT, 2011.

MESQUITA, A.S. Resíduos tóxicos industriais organoclorados em Samaritá: um problema de saúde pública. Dissertação de mestrado, Faculdade de Saúde Pública da Universidade de São Paulo, 1994.

PRANDI, Maria Lúcia. Deputada; Jornal A Tribuna de Santos, 2006.

REGITANO, R.L.O. E BARBOSA, T.M.L. Influência da classe e profundidade do solo na degradação do inseticida - Nematicida aldicarb. Pesquisa Agropecuária Brasileira. V.29, 1994.

SANTOS, Antônio Silveira Ribeiro dos. Programa Ambiental: A Ultima Arca de Noé, 1999. Disponível em: http://www.aultimaarcadenoe.com/desenvolvimento.htm. Acesso em 16/08/08. 